\title{
Art therapy: the benefits for sick children
}

\begin{abstract}
To draw is one of the favourite games of children, it performs two functions: a function of releasing, in which the child actively reproduces an unpleasant experience, and the anguish can be externalized. The second function is symbolic in which the children immerse themselves in a fantasy world where every desire can be accommodated and realized, creating a symbolic play, through which the child can express emotions. In most cases, drawings and other handicrafts help us to understand and appreciate the improvement in the child's feelings that comes from the environment, from the psychosocial support closely linked to the achieved results, and from the overall help strategy developed within the Department for the whole family. For this reasons it is an important therapeutic tool. It promotes the therapeutic alliance and allows the child liberation like a "catharsis" of anger, discontent, and fear. It allows the patient to speak freely and it causes the awareness of hidden conflicting reality that is the basis of the specific neurotic or psychotic problem of the child.
\end{abstract}

Keywords: art therapy, pediatric cancer
Volume 6 Issue 2 - 2016

\author{
Daniela Caprino, Franecsa G Naselli, Luisa \\ Massimo \\ Department of Pediatric Hematology Oncology, Gaslini \\ Children?s Hospital, Italy
}

Correspondence: Daniela Caprino, Department of Pediatric Hematology Oncology, Gaslini children?s Hospital, Genova, Italy, Tel 3900000000000,Email danielacaprino@gaslini.org

Received: April 29, 2016 | Published: June 24, 2016

\section{Mini review}

"Color directly influences the soul. Color is the keyboard, the eyes are the hammers, the soul is the piano with many strings. The artist is the hand that plays, touching one key or another purposively, to cause vibrations in the soul." (W. Kandinsky, Concerning the Spiritual in Art).

Art therapy uses creative expression to provide individuals with a safe outlet for expressing thoughts and emotions to successfully facilitate recovery from psychological distress. It is an intervention method that traditionally has drawn from psychoanalytic theory for its framework and procedures. A breadth of current art therapies, informed by a variety of theoretical paradigms, share a common procedure that uses creative art as a method for promoting expression and healing. Art is a natural form of self expression for children - it is one way that allows them to interact with, and understand their environment. For the child to draw is a form of game, for example M. Klein does not distinguish in interpretation between game and drawing although there are some experiences that show as there are differences between the graphic processing and imaginative elaboration. To draw is one of the favorite game of children, and as a game can be used in psychotherapy. It performs two functions: a function of releasing, in which the child actively reproduces an unpleasant experience he suffered, and the anguish can be externalized. The second function is symbolic in which the children immerse themselves in a fantasy world where every desire can be accommodated and realized through the temporarily and partially lack of the reality principle and the precepts of the superego, to create a symbolic play, thanks to which the child can express emotions functional to its welfare. ${ }^{1}$

Some therapists consider the drawing as privileged access to the child's unconscious. ${ }^{2}$ It leaves a place where the children express themselves and in a later time, the therapist can try to decipher and use it, in the way the children give the key to his unconscious message. In the drawing the child can build an imaginary scenario in which he is always present with his/her real needs, perceptions or fears, desires, aspirations, memories and his/her own experience (as a projection design). Children draw an inner reality and not just visual; the real object ends up having a simple function of stimulus. The child projects into the design as: "the child casts over all wonderful things that he/ she carries within". In this sense, the children project their self-image in a space: so the design becomes the "story" that children tell. The process of art therapy provides a safe vehicle by which the therapist and child are able to form a therapeutic bond. Throw the artistic effort the child can express experiences, memories, and emotions providing a common language by which the child and therapist can communicate. ${ }^{3}$ For these reasons it is an important therapeutic tool. It promotes the therapeutic alliance and allows the child liberation like a "catharsis" of anger, discontent, fear ... It allows the patient to speak freely and it causes the awareness of hidden conflicting reality, that are the basis of the specific neurotic or psychotic problem of the child.

Winnicott developed a type of intervention called "squiggle game" aimed to create a space where it is possible to express the playful potential of the infant mind. When this happens the child opens entirely and creates a relationship with the therapist dense, full and confident. Psychotherapy takes place in the overlap of two areas of playing, that of the patient and that of the therapist. Psychotherapy has to do with two people playing together. The corollary of this is that where playing is not possible then the work done by the therapist is directed towards bringing the patient from a state of not being able to play into a state of being able to play. (from "Playing: Its Theoretical Status in the Clinical Situation," 1971).

The game is in general the preferred tool to communicate with the child and it is more effective for sick children. Playing and to drawing allow them to go through the experience of the disease without succumbing or experienced the distressing situation of incommunicability. According to the interpretations of psychoanalytic tradition the ability to play and draw can be a useful indicator of the degree of psychological distress of the child. ${ }^{4,5}$ Cancer diagnosis could be considered a traumatic event that disrupts everyday life due to the frequent hospitalizations that are needed. In some cases, this involves moving from familiar surroundings in order to be near a hospital, which results in the loss of familiar objects, school and peers. The sick child may perceive the anxiety felt by his/her parents that is linked to the diagnosis, the prognosis and the uncertainty of how effective therapy will be. ${ }^{6}$

On the psychological point of view the condition of a suffering body and the risk of death represent catastrophic experience; especially because if it happens during the evolutionary phase in which, according to the dynamic theories, the infant lived in the registry of its own omnipotence. ${ }^{7}$ These experiences can then be amplified by the feeling of the child to be impotent in facing the disease, because 
of the pain, anxiety, physical symptoms and unwanted side effects of treatments. The opportunity of expressing the anguish, however, can be very different from patient to patient. Every one of all ages use different personal styles based on their own temperaments in coping with the vicissitudes of life. ${ }^{8}$ According to observations of clinical psychodynamic tradition, the children, especially in latency phase, are able to maintain a sort of double track in understanding their disease: ${ }^{9}$ one side they have to organize their defenses mechanisms away from the field of conscious, moving fears, pain. On the other side, they need not to be alone in front of anxiety and emotions that parents or sanitary staff (physicians nurses) can understand without being overwhelmed by fear and help them to cope with. ${ }^{10}$ Defenses organized around to be a "good patient", which in fact reassures all adults, can be interpreted, according to a dynamic perspective, as distress systematically denied, that could reappears again in subsequent periods as anxiety disturb or as psychopathological symptom. Art Therapy could be seen as a powerful tool for encouraging hospitalized children. Observing sick children while they play and draw has only recently been considered important.

Through art therapy, children can also learn how to manage difficult emotions such as fear and anger, and they also learn coping responses through visual images, especially when they have difficulties verbalizing these situations. ${ }^{11}$ In such a troublesome situation a child uses verbal communication cautiously, at times he/she feels fear and embarrassment around strangers and around his/her own parents, especially when they are speaking with the health care professionals. Moreover inside a hospital a child feels like a stranger because of the uneasiness that accompanies his/her new experience. A good communication is essential in order to establish any type of alliance. This includes both the therapeutic alliance and the agreement between patients and caregivers that lead to mutual fulfillment. Learning how to communicate with each child is pivotal for good and safe health care. Nonetheless, since the need to communicate still remains, body language or other forms of expression are put into use, creating a graphic and pictorial form of communication. ${ }^{12,13}$ Their need for truth unfolds through artistic signs. Art therapy is the preferred and ideal means of communication with children. The use of the common language of art may facilitate the development of a relationship with the therapist. This result can be achieved with the help of nonverbal tools, such as play, drawings and other handicraft activities in order to establish a positive therapeutic alliance with the caregivers.

The language of children is unsophisticated. They express themselves through drawings, using them as a stage to dramatize their requests, needs, wishes, anxieties, and joys. They also use symbols and images to represent elements in circumstances they are trying to understand. The opportunity to express themselves through drawings makes the sick children their own therapeutic agent through a self healing mechanism. ${ }^{14}$

Perception of the disease, as well as fears and hopes emerge. The comments written by each adolescent and school-aged child, or by the play worker allow us to acquire a better understanding of the painter's meaning and feelings. ${ }^{15}$ Some very interesting data may emerge from longitudinal studies because each child makes several paintings over the course of the year, in different health and emotional states such as disease onset, remission, off-treatment, and relapse. In most cases, drawings and other handicrafts help us to understand and appreciate the improvement in the child's feelings that comes from the environment, from the psychosocial support closely linked to the achieved results, and from the overall help strategy developed within the Department for the whole family. A family-centered approach is important for them in order to ensure adjustment and coping, and to avoid post-traumatic stress, and the onset of side effects linked to an unknown internal psychological distress. ${ }^{16}$ As Jung suggests, consciousness can be reached more quickly through handiwork than through intellect. ${ }^{17}$ Therefore, art therapy should be taken into account and included it in the total care of all children affected by diseases that require long periods of hospitalization.

\section{Acknowledgments}

None.

\section{Conflicts of interest}

Author declares there are no conflicts of interest.

\section{Funding}

None.

\section{References}

1. Crocetti G. Il bambino nella pioggia. Il significato del disegno infantile nel dialogo terapeutico, Armando Editore, Roma. 2001.

2. Morgenstern S. Psychoanalyse infantile, symbolisme et valeur clinique des creation imaginaires chez l'enfant, Denoel, Parigi. 1937.

3. Leslie G Eaton, Kimberly L Doherty, Rebekah M Widrick. A review of research and methods used to establish art therapy as an effective treatment method for traumatiz ed children. The Arts in Psychotherapy. 2007;34:256-262.

4. Gamba A. "Il disegno ed il bambino malato di tumore", in Associazione Italiana di Ematologia e Oncologia Pediatrica, a cura di R. Saccomani, Tutti bravi. Psicologia e clinica del bambino portatore di tumore, Cortina, Milano, Italy. 1998.

5. Giacon B. "L'esperienza di malattia nel bambino e nell'adolescente", In: Basso G, et al. (a cura di), Guida all'assistenza dei bambini e degli adolescenti malati di tumore, Cortina, Milano, Italy. 2012.

6. Sarid O Huss E. Trauma and acute stress disorder: A comparison between cognitive behavioral intervention and art therapy. The Arts in Psychotherapy . 2010;37:8-12.

7. Ciccone A, Lhopital M. La nascita alla vita psichica. Borla, Roma, Italy. 1991.

8. Odero, Clerici, Ripamonti. "Gli atteggiamenti dei bambini nei riguardi della morte", Bambini. 2005;86(1):12-19.

9. Gelli P, Clerici CA, Albasi C, et al. "L'intervento psicologico-clinico in ospedale con il bambino affetto da una malattia organica: teoria, tecnica e prassi", in Abilitazione e Riabilitazione. 2004;13(2):61-70.

10. Clerici CA, Veneroni L. La psicologia clinica in ospedale. Consulenza e modelli di intervento, Il Mulino, Bologna. 2014.

11. Eaton LG, Doherty KL, Widrick RM. A review of research and methods used to establish art therapy as an effective treatment method for traumatized children. The Arts in Psychotherapy. 2007;34: 256-262.

12. Subbotsky E, Hysted C, Jones N. Watching films with magical content facilitates creativity in children. Percept Mot Skill. 2010;111(1):261-277.

13. Ewing B. Children's wishes: holistic revelations in art. J Holist Nurs. 2008;26(2):147-154.

14. Huss E, Nuttman-Shwartze O, Altman A. The role of collective symbols as enhancing resilience in children's art. The Arts in Psychotherapy. 2012;39:52-59.

15. Alavinezhada R, Mousavia M, Sohrabib N. Effects of art therapy on anger and self-esteem in aggressive children Proc. Social Behavioral Sciences. 2014;113:11-117. 
16. Wilson ME, Megel ME, Enenbach L, et al. The voices of children: stories about hospitalization. J Pediatr Health Care. 2010;24(2):95-102.
17. Jung CG. "The practice of psychotherapy" NJ Princeton University. 1966. 